\title{
Knowledge and attitude toward breastfeeding benefits as factors linked to the intention to lactate, in pregnant women in Leon, Guanajuato-a cross-sectional study
}

\author{
Ana K. Mancera-Navarro and Fátima del C. Aguilar-Díaz* \\ Public Health Department, National School of Higher Learning Campus Leon, Universidad Nacional Autónoma de México, Leon, Guanajuato, Mexico
}

\begin{abstract}
Objectives: The objective of the study is to identify the association between the knowledge and attitude of pregnant women regarding the health benefits of breastfeeding in their own health and on the newborn with the intention of breastfeeding. Materials and methods: $A$ cross-sectional study. Pregnant women attending at CASES Leon, Guanajuato participated. Data regarding knowledge and attitude about breastfeeding and breastfeeding intention was collected using previously validated structured questionnaires. In addition, sociodemographic information such as age, marital status, schooling, occupation, and socioeconomic status was gathered. Results: One hundred and eighty-two pregnant women participated; mean age was $23.9 \pm 6.1$ years. $27.7 \%$ were married; $72.0 \%$ were housewives; $54.4 \%$ had a high school degree. Regarding general knowledge about breastfeeding, half of them had a medium level. $78 \%$ had a neutral attitude towards breastfeeding, and $18.1 \%$ of the participants had a firm intention to breastfeed. The intention to breastfeed was associated with age $(p=0.047)$, occupation ( $p=0.017)$, number of children $(p=0.024)$ socioeconomic level $(p=0.020)$ and attitude towards $B F(p=0.037)$. Conclusions: Pregnant women have proper knowledge about the benefits that BF offers. However, knowledge about the benefits of BF on the health of the baby and the mother can be improved. Less than half of the participants intended to breastfeed their children exclusively. Housewives were more likely to have a firm intention to breastfeed. Likewise, those who have a positive attitude towards BF also have this probability. For each year that pregnant women age, the likelihood that they will BF decreases.
\end{abstract}

Key words: Exclusive breastfeeding. Breastfeeding. Knowledge. Attitudes. Intention. Cross-sectional

\section{Introduction}

In 2002, the World Health Organization released the "Infant and Young Child Feeding program," which states breastfeeding is the only recommended source of food for infants for at least their first four to six months of life, referring to this as exclusive breastfeeding (EBF) ${ }^{1}$. In a like manner, the United Nations International Children's
Emergency Fund in Mexico mentions that EML is essential for the growth and development of children, which in addition to being the best food for them, offers significant benefits for the physical and emotional health of the mothers ${ }^{2}$.

Breastfeeding offers multiple benefits for the baby as well as for the mother ${ }^{3}$. Some of the benefits for the mother include a lower risk of breast and ovary cancer

\section{Correspondence:}

*Fátima del C. Aguilar-Díaz

E-mail: faguilar@enes.unam.mx license (http://creativecommons.org/licenses/by-nc-nd/4.0/).
Date of reception: 07-07-2021

Date of acceptance: 04-10-2021 DOI: 10.24875/RMU.21000033
Available online: 01-12-2021 Medicina Universitaria. 2021;23(4):133-141 www.medicinauniversitaria.org is is an open access article under the CC BY-NC-ND 
and a lower risk of postpartum hemorrhages, to name a few ${ }^{4}$. Benefits for the baby include adequate nutrition ${ }^{4}$, lower risk of developing diseases such as otitis media, respiratory infections, asthma, obesity, and Type I and II diabetes ${ }^{5,6}$. Moreover, it also provides benefits for the infant's oral health, such as a correct development of the maxillaries, instauration of the nasal breathing pattern, maturation of the masticatory muscles, mandibular advance, and correct development of dental arches ${ }^{7,8}$.

Despite the multiple benefits of $\mathrm{BF}$, estimations show that, worldwide, only around $38 \%$ of infants between the ages of 0-6 months of age are exclusively breastfed ${ }^{9}$. In Mexico, evidence shows that there has been an alarming decline in these practices, with the lowest rates of EBF in infants under 6 months in the American continent ${ }^{10}$. Different studies suggest that one way to mitigate this problem would be to concentrate on identifying and improving knowledge (according to the socioeconomic level and occupations of the pregnant women) $)^{11-13}$ and attitudes that the mothers have since these are modifiable factors ${ }^{14}$. Moreover, attitude is a predictive indicator of feeding choice and duration of $\mathrm{BF}^{14,15}$ and influences the intention ${ }^{16}$.

The Theory of Planned Behavior is widely used to predict breastfeeding practices in transcultural environments. According to this theory, the intention to breastfeed is an immediate precursor to maternal lactation. Comprehending these factors and the specific determinants of the infant's nourishment is crucial for developing more efficient programs to promote breastfeeding and information for the implementation of adequate policies ${ }^{17,18}$.

Therefore, the objective of this paper was to identify the association between knowledge and attitude towards the benefits of breastfeeding, with the intent to lactate in pregnant women in Guanajuato, Mexico.

\section{Materials and methods}

This paper was approved by the Research Ethics Commission at the National School of Higher Learning, Leon branch, with the registry CEI.18_012_S, and by the Research Committee at the Health Jurisdiction VII of the León Guanajuato municipality, with the authorization number JSVII-01-220119.

\section{Design and location of the study}

A transversal study was conducted in León, Guanajuato, between January and October of 2019.

\section{Participants}

Pregnant attendees from the pregnancy club at the Care Center for Essential Health Services (CAISES by its Spanish acronym) participated. The women were invited to participate, explaining to them the investigation's objective, process, and duration. After this, we obtained signed informed consents. These included: pregnant women aged 15 and 40 , those who were in their last trimester of gestation, both primiparous and multiparous, who voluntarily accepted to participate in this study and who signed the informed consent; in the case of underage patients, we obtained verbal consent to participate in the survey from the pregnant women and the signature of their corresponding tutor. On the other hand, there were excluded pregnant women with physical or mental alterations which would impede them from answering the questionnaire. Furthermore, we excluded questionnaires with missing or incomplete data.

\section{Measurement tools}

Different instruments were utilized for data collection. The first one was created based on a questionnaire about general knowledge of breastfeeding and its health benefits in both the mother and the infant ${ }^{19}$. Said questionnaire consisted of 24 questions, divided into three sections: (a) general knowledge of breastfeeding ( 6 questions, with a score between 0 and 6); (b) knowledge of the benefits of maternal lactation in the health of the infant (13 questions, with a score between 0 and 52); (c) knowledge of the benefits of maternal lactation in the mother's health (five questions, with a score between 0 and 20).

The second questionnaire used to assess attitude toward breastfeeding was the "Infant Feeding Attitude Scale" in the Mexican population, a validated adaptation from the lowa Infant Feeding Attitude Scale ${ }^{20}$, with 17 items with Likert-like responses from 1 to 5 . Scores range between 17 to 85 points and are categorized in: positive to artificial lactation (17-48); neutral (49-69), and positive to maternal lactation (70-85).

In addition, the Infant Feeding Intentions questionnaire ${ }^{21}$ was also employed, which included five questions with Likert-like responses, with scores from 0 to 16 , being categorized as very low (0-3.5); low (4.0-7.5); moderate (8.0-11.5); strong (12.0-15.5) and very strong (16).

Finally, and given the fact that there were no previously designed questions for evaluating the benefits of 
maternal lactation in the infant's oral health, we created, validated, and obtained, based on a review of the literature ${ }^{22,23}$, five questions for that purpose. Therefore, a reliability analysis was performed considering two stages. First, the internal consistency of the questionnaire was estimated using the Alpha Cronbach coefficient ( $\alpha$-Cronbach), obtaining a value of 0.88 . Second, a test-retest was conducted to determine the repeatability of the questionnaire using the Intraclass Correlation Coefficient getting a value of 0.82 . In the same way, the Kappa index test was conducted for the concordance between items, obtaining values of $>0.80$.

In addition to the questionnaires previously mentioned, a section for collecting sociodemographic data (age, marital status, education, and occupation) and socioeconomic status following the Socioeconomic Status index created by the Mexican Association of Market Intelligence and Opinion Agencies (AMAl by its Spanish acronym) was included. The average time to complete the questionnaire was $13 \mathrm{~min}$.

\section{Statistical analysis}

The data were captured and later analyzed using the SPSS v.22 software. For the analysis, descriptive measures were calculated according to the nature of the variables. Bivariate analyses were performed using the $\mathrm{Chi}^{2}$, subsequently, a logistic regression model was made. The dependent variable was a dichotomized intention to lactate (very strong-strong versus moderate-low-very low), and independent variables were: age, occupation, socioeconomic status, the mother's attitude towards breastfeeding, general knowledge of $\mathrm{BF}$, knowledge of the benefits of $B F$ for the mother, for the general health of the baby, for the oral health of the baby; desired pregnancy, number of children and educational level. The significance level was set at $p<0.05$ value.

\section{Results}

\section{Characteristics of the sample}

A total of 206 pregnant women were surveyed; however, 24 were eliminated since they did not have a complete registry of the requested data. Thus, the analysis included 182 participants, with a mean age of 23.9 \pm 6.1 years. $29.1 \%$ reported being married, $72 \%$ were housemakers, $51.1 \%$ completed junior high school, and $36.8 \%$ of the participants reported a Socioeconomic status of "C" (Table 1). In addition, $90.6 \%$ reported to have had a wanted pregnancy, and $52.9 \%$ were in their first pregnancy.

\section{Knowledge}

A total of $66.5 \%$ of the pregnant women acknowledged that the baby should be fed with EBF for the first six months of life, $22 \%$ of the surveyed women mentioned that this practice ought to continue until the baby is a year old. The rest believed that it should stop at three months of age. Regarding the introduction of complementary food, $68.7 \%$ of the women considered that this practice should start when the baby is six months, $20.3 \%$ believed that this should be put off until the baby was one year old. Concerning the scores for the knowledge, we obtained a mean of $38.9 \pm 6.7$ in the score of knowledge of the benefits of EBF in newborns; $13.6 \pm 2.9$ in the knowledge about the benefits for the mother; $15.0 \pm 3.3$ in the knowledge about the benefits in babies oral health. These values were reclassified to obtain the following categories: high, medium, and low level of knowledge, divided by percentiles, extreme of $25 \%$, and center of $50 \%$, according to the distribution of the responses from the mothers. For the general knowledge of the BF section, we considered the following levels: $0-3=$ low, $4-5=$ medium, and 6 = high level.

Concerning knowledge about the benefits of $\mathrm{BF}$ in the baby's health: 0-35 = low level, 36-43 = medium level, and 44-52 = high level. Knowledge about the benefits of BF in the mother's health, scores: 0-11 = low level, 12-16 = medium level, and 17-20 = s high level. Lastly, for knowledge about the benefits of BF in the baby's oral health, categorization was: $0-13=$ low, $4-18=$ medium, and 19-20 = high level.

Findings show that $50.6 \%$ had a medium level of knowledge regarding general $\mathrm{BF} ; 44 \%$ concerning the benefits in the baby's health; $45.1 \%$ on the benefits of breastfeeding in the baby's oral health and $57.7 \%$ about the benefits of BF in the mother's health (Table 2).

\section{Attitude and intention to lactate}

Regarding the attitude toward breastfeeding, it was found that $78 \%$ of them had a neutral attitude, and the rest had a positive attitude. Almost half (45.1\%) had a very strong intention, while $24.5 \%$ were strong, $7.1 \%$ were low, and $2.2 \%$ were very low. In addition, $46.1 \%$ of pregnant women intend to exclusively breastfeed for up to 6 months. 
Table 1. Distribution of sociodemographic variables in the pregnant women surveyed in the period of January-August 2019 ( $n=182)$

\begin{tabular}{|c|c|c|c|c|c|c|c|}
\hline \multicolumn{2}{|l|}{ Civil State } & \multicolumn{2}{|c|}{ Education } & \multicolumn{2}{|c|}{ Occupation } & \multicolumn{2}{|c|}{ Socioeconomic Level (AMAI)* } \\
\hline & n (\%) & & n (\%) & & n (\%) & & n (\%) \\
\hline Single & $39(21.4)$ & No studies & $1(0.5)$ & Laborer & $22(12.1)$ & $A / B$ & $16(8.8)$ \\
\hline Married & $53(29.1)$ & Primary & $29(15.9)$ & Technician & $1(0.5)$ & C & $67(36.8)$ \\
\hline \multirow[t]{4}{*}{ Free Union } & $90(49.5)$ & Secondary & $93(51.1)$ & Professional & $6(3.3)$ & $\mathrm{C}_{+}$ & $60(33.0)$ \\
\hline & & High School & $42(23)$ & Student & $7(3.8)$ & C- & $20(11.0)$ \\
\hline & & University & $17(9.3)$ & Housewife & $131(72.0)$ & $\mathrm{D}$ & $2(1.1)$ \\
\hline & & & & Other & $15(8.2)$ & $\mathrm{D}_{+}$ & $17(9.3)$ \\
\hline Total & $182(100)$ & & $182(100)$ & & $182(100)$ & & $182(100)$ \\
\hline
\end{tabular}

*Index of Socioeconomic Levels created by the Mexican Association of Market Intelligence and Opinion agencies. A/B and D are considered the best and worst socioeconomic status respectively.

Table 2. Level of knowledge of breastfeeding observed in the pregnant women surveyed in the period of January-August 2019 ( $n=182$ )

\begin{tabular}{|l|c|c|c|c|}
\hline & $\begin{array}{c}\text { High } \\
\mathbf{n}(\%)\end{array}$ & $\begin{array}{c}\text { Medium } \\
\mathbf{n}(\%)\end{array}$ & $\begin{array}{c}\text { Low } \\
\mathbf{n}(\%)\end{array}$ & $\begin{array}{c}\text { Total } \\
\mathbf{n}(\%)\end{array}$ \\
\hline General knowledge of breastfeeding & $77(42.3)$ & $92(50.6)$ & $13(7.1)$ & $182(100)$ \\
\hline Knowledge about the benefits of BF in the baby's health & $44(31.9)$ & $80(44.0)$ & $58(24.2)$ & $182(100)$ \\
\hline Knowledge of the benefits of BF in maternal health & $31(17.0)$ & $105(57.7)$ & $46(25.3)$ & $182(100)$ \\
\hline Knowledge of the benefits of BF in the baby's oral health & $39(21.4)$ & $82(45.1)$ & $61(33.5)$ & $182(100)$ \\
\hline
\end{tabular}

In the bivariate analysis, some categories of the sociodemographic variables were merged, such as schooling, occupation, socioeconomic level, and the intention to breastfeed, since there were very few cases in some of these.

A significant difference was observed in the intention to breastfeed according to the occupation ( $p=0.033$ ). A higher percentage of pregnant housewives had a very strong or strong intention to breastfeed compared to those with a different occupation (Table 3).

A significant difference was found between the intention to breastfeed with the knowledge about the benefits of BF on the oral health of the baby $(p<0.001)$. It was observed that $82.1 \%$ of pregnant women who had high knowledge about the benefits of BF towards the baby's oral health had a very strong or strong intention to breastfeed compared to $45.9 \%$ who had low knowledge (Table 4).
In the multivariate analysis, carried out through a logistic regression model, it was found that the intention to breastfeed was associated with age, being that, for each year of increase in the age of the pregnant women, the probability of belonging to the very strong and strong intention group decreases $0.07 \%(\mathrm{OR}=0.933, \mathrm{p}=$ 0.047). Likewise, the participants with an occupation other than a housewife had 3 times the probability of having a moderate, low, and very low intention to breastfeed compared to those who were dedicated to the home $(p=0.017)$. Similarly, pregnant women who show a positive attitude towards BF were more than twice as likely to have a very strong or strong intention to breastfeed $(p=0.048)$ compared to those who had a neutral attitude towards BF. Regarding the socioeconomic level, it was observed that pregnant women who were classified within levels $C$ and $C$ - were less likely to have a very strong and strong intention compared to those who 
Table 3. Association between the intention to breastfeed and the sociodemographic aspects of the pregnant women surveyed in the period of January-August $2019(n=182)$

\begin{tabular}{|c|c|c|c|c|c|c|}
\hline \multicolumn{7}{|c|}{ Civil State } \\
\hline Intention to breastfeed & $\begin{array}{l}\text { Single } \\
\mathrm{n}(\%)\end{array}$ & $\begin{array}{l}\text { Married } \\
\mathrm{n}(\%)\end{array}$ & \multicolumn{2}{|c|}{$\begin{array}{l}\text { Free Union } \\
\text { n (\%) }\end{array}$} & $\begin{array}{l}\text { Total } \\
\text { n (\%) }\end{array}$ & p-value* \\
\hline Very strong-Strong & $27(23.5)$ & $32(27.8)$ & \multicolumn{2}{|c|}{$56(48.7)$} & $115(100)$ & \multirow[t]{2}{*}{0.661} \\
\hline $\begin{array}{l}\text { Moderate-Low and Very } \\
\text { Low }\end{array}$ & $12(17.9)$ & $21(31.3)$ & \multicolumn{2}{|c|}{$34(50.8)$} & $67(100)$ & \\
\hline \multicolumn{7}{|c|}{ Level of Education } \\
\hline & $\begin{array}{c}\text { None/Primary } \\
\text { n (\%) }\end{array}$ & $\begin{array}{l}\text { Secondary } \\
n(\%)\end{array}$ & \multicolumn{2}{|c|}{$\begin{array}{c}\text { High School/University } \\
\text { n (\%) }\end{array}$} & $\begin{array}{l}\text { Total } \\
\text { n (\%) }\end{array}$ & p-value* \\
\hline Very strong-Strong & $20(17.4)$ & $55(47.8)$ & \multicolumn{2}{|c|}{$40(34.8)$} & $115(100)$ & \multirow[t]{2}{*}{0.509} \\
\hline $\begin{array}{l}\text { Moderate-Low and Very } \\
\text { Low }\end{array}$ & $10(14.9)$ & $38(56.7)$ & \multicolumn{2}{|c|}{$19(28.4)$} & $67(100)$ & \\
\hline \multicolumn{7}{|c|}{ Occupation } \\
\hline & \multicolumn{2}{|l|}{$\begin{array}{l}\text { Housewife } \\
\text { n (\%) }\end{array}$} & \multicolumn{2}{|l|}{$\begin{array}{l}\text { Other } \\
\mathrm{n}(\%)\end{array}$} & $\begin{array}{l}\text { Total } \\
\text { n (\%) }\end{array}$ & p-value* \\
\hline Very strong-Strong & \multicolumn{2}{|l|}{89 (77.4) } & \multicolumn{2}{|l|}{$26(22.6)$} & $115(100)$ & \multirow[t]{2}{*}{0.033} \\
\hline $\begin{array}{l}\text { Moderate-Low and Very } \\
\text { Low }\end{array}$ & $42(62.7)$ & & \multicolumn{2}{|l|}{$25(37.3)$} & $67(100)$ & \\
\hline \multicolumn{7}{|c|}{ Socioeconomic Level* } \\
\hline & $\begin{array}{l}\text { A/B, C } \\
\text { n (\%) }\end{array}$ & $\begin{array}{c}\text { C+ } \\
\text { n (\%) }\end{array}$ & $\begin{array}{c}\text { C- } \\
\text { n (\%) }\end{array}$ & $\begin{array}{l}D+, D \\
\text { n (\%) }\end{array}$ & $\begin{array}{l}\text { Total } \\
\text { n (\%) }\end{array}$ & p-value* \\
\hline Very strong-Strong & $49(42.6)$ & $39(33.9)$ & $11(9.6)$ & 16 (13.9) & $115(100)$ & \multirow[t]{2}{*}{0.180} \\
\hline $\begin{array}{l}\text { Moderate-Low and Very } \\
\text { Low }\end{array}$ & $34(50.7)$ & $21(31.3)$ & $9(13.4)$ & $3(4.5)$ & $67(100)$ & \\
\hline${ }^{*}$ Pear & & & & & & \\
\hline
\end{tabular}

Index of Socioeconomic Levels created by the Mexican Association of Market Intelligence and Opinion agencies. A/B and D are considered the best and worst socioeconomic status respectively.

belong to higher levels $(A, B$, and $C)(p<0.05)$. Furthermore, for each pregnant woman's child, the probability of having a very strong and strong intention decreased by more than $50 \%(\mathrm{OR}=0.459, \mathrm{p}=0.024)$ (Table 5$)$.

\section{Discussion}

The beginning and maintenance of $\mathrm{BF}$ is a vulnerable process. Different factors may cause many women who wish to breastfeed to fail at it ${ }^{21,22}$. The intention to lactate is a decisive factor for BF practice and has a special connection to the duration of $\mathrm{EBF}^{14,15}$. Therefore, the present study evaluated the knowledge and attitude towards breastfeeding in pregnant women in the city of León, Guanajuato to determine the factors linked to the intention to breastfeed among this population. To our understanding, this is the first study evaluating the knowledge that pregnant women have regarding BF benefits in the baby's oral health.

Among the most significant results, we can highlight is that 5 out of every 10 pregnant women had a medium level of knowledge about BF in general. Comparable to that reported in other studies, finding a similar percentage of women with a regular knowledge in Mexican populations as well as other countries ${ }^{12}$. Moreover, within this study group, it was noticeable that most pregnant women had medium or high knowledge about the benefits of BF in the baby's health, like that reported by Aznar et al. ${ }^{13}$ who observed that most mothers knew the advantages that breastfeeding offers.

On the other hand, as previously mentioned, this is the first study evaluating the knowledge that pregnant women have concerning BF benefits in the baby's oral health. Our findings showed that pregnant women have 


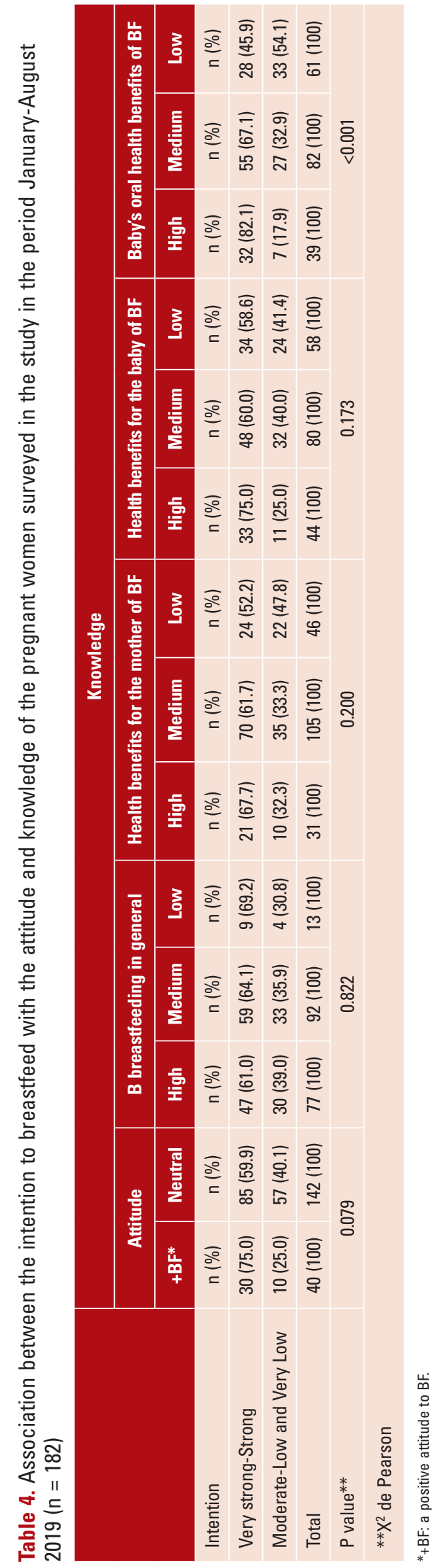

a medium level of knowledge in this topic. Hence, it would be recommendable to deepen this aspect, highlighting the importance of BF in the baby's oral health in the long term.

Regarding the attitude towards $\mathrm{BF}$, most of the women showed a neutral attitude. Contrary to the results obtained by Gerónimo et al. ${ }^{11}$ in pregnant women in Tabasco, who mostly had a positive attitude, despite having similar sociodemographic characteristics. Maybe this difference is due to prenatal counseling about BF, it is possible that the content of the counselors had been different; however, this was not reported. In our study group, particular emphasis was made on the benefits that BF brings the mother and the baby, and not so much on the properties of breast milk and the benefits of BF in social and cultural environments. Another possibility is that pregnant women have forgotten the information provided during BF counseling, especially those who received said information long ago ${ }^{24}$.

Regarding the intention to breastfeed, it is worth noting that almost all pregnant women had the intention to do so; however, less than half reported having the intention to practice EBF. A situation that has been reported in other studies ${ }^{25,26}$. Additionally, it is noteworthy that the intention to breastfeed was linked to occupation. Housewives expressed a greater intention to lactate. This result may be because these mothers usually share more time with their babies ${ }^{27}$, while those pregnant women who report a different occupation must return to work. In our study population, it was noticeable that almost half of the women with a low breastfeeding intention are not housewives, but have a different occupation.

Conversely, similar to other populations ${ }^{28}$, the intention to lactate was not linked to marital status. Nevertheless, it is important to mention that in our study population, most of the participants were living with a stable partner in a relationship. This finding is relevant as family and spousal support are considered two substantial components for the proper development of the mother in her new stage of life ${ }^{29}$.

Some of the limitations of this study include the fact that the study sample was selected by convenience. Thus the conclusions cannot be generalized to the general population. Another limitation derived from the study's design was the possible overestimation of the obtained odds ratio values.

In addition, sexual differences in the knowledge and the attitude towards BF were not evaluated in this study. The recommendation for future studies is to assess these constructs among men since they can influence 
Table 5. Logistic regression model. Factors associated with the intention to breastfeed/very strong-strong vs moderate, low and very low of the pregnant women surveyed in the period January-August $2019(\mathrm{n}=182)$

\begin{tabular}{|c|c|c|c|c|}
\hline \multirow[t]{2}{*}{ Variables } & \multirow[t]{2}{*}{$\mathbf{O R}^{* *}$} & \multicolumn{2}{|c|}{$95 \%$ confidence interval for OR } & \multirow[t]{2}{*}{ p-value* } \\
\hline & & Lower & Upper & \\
\hline Age & 0.933 & 0.871 & 0.999 & 0.047 \\
\hline $\begin{array}{l}\text { Occupation } \\
\text { Housewife } \\
\text { Other }\end{array}$ & $\begin{array}{c}-- \\
0.375\end{array}$ & $\begin{array}{c}-- \\
0.167\end{array}$ & $\begin{array}{c}-- \\
0.840\end{array}$ & $\begin{array}{c}-- \\
0.017\end{array}$ \\
\hline $\begin{array}{l}\text { Educational level } \\
\text { High school/University } \\
\text { None/Primary } \\
\text { Secundary }\end{array}$ & $\begin{array}{c}-- \\
0.961 \\
1.269\end{array}$ & $\begin{array}{c}-- \\
0.361 \\
0.405\end{array}$ & $\begin{array}{c}-- \\
2.561 \\
3.974\end{array}$ & $\begin{array}{c}-- \\
0.937 \\
0.683\end{array}$ \\
\hline $\begin{array}{l}\text { First pregnancy } \\
\text { Yes }\end{array}$ & 0.297 & 0.080 & 1.102 & 0.070 \\
\hline $\begin{array}{l}\text { Number of children } \\
\text { Number of children }\end{array}$ & 0.459 & 0.233 & 0.904 & 0.024 \\
\hline $\begin{array}{l}\text { Wanted pregnancy } \\
\text { Yes }\end{array}$ & 0.732 & 0.219 & 2.450 & 0.612 \\
\hline $\begin{array}{l}\text { Socialeconomic Level (A) } \\
\text { AMAI }(A, B, C) \\
\text { AMAI (C-) } \\
\text { AMAI }(C+) \\
\text { AMAI }(D, D+)\end{array}$ & $\begin{array}{l}-\overline{-} \\
0.165 \\
0.114 \\
0.223\end{array}$ & $\begin{array}{c}-- \\
0.036 \\
0.020 \\
0.048\end{array}$ & $\begin{array}{l}-- \\
0.749 \\
0.665 \\
1.029\end{array}$ & $\begin{array}{c}-- \\
0.020 \\
0.016 \\
0.054\end{array}$ \\
\hline $\begin{array}{l}\text { Attitude toward BF } \\
\text { Positive to BF } \\
\text { Neutral }\end{array}$ & $\begin{array}{c}2.506 \\
--\end{array}$ & $\begin{array}{c}1.036 \\
--\end{array}$ & $\begin{array}{c}6.543 \\
--\end{array}$ & $\begin{array}{c}0.048 \\
--\end{array}$ \\
\hline $\begin{array}{l}\text { Knowledge BF Benefits o } \\
\text { High } \\
\text { Medium } \\
\text { Low }\end{array}$ & $\begin{array}{c}-- \\
1.143 \\
0.247\end{array}$ & $\begin{array}{c}--- \\
0.514 \\
0.020\end{array}$ & $\begin{array}{c}-- \\
2.541 \\
3.072\end{array}$ & $\begin{array}{l}-- \\
0.743 \\
0.277\end{array}$ \\
\hline $\begin{array}{l}\text { General Knowledge of } \mathrm{BP} \\
\text { High } \\
\text { Medium } \\
\text { Low }\end{array}$ & $\begin{array}{l}-- \\
0.937 \\
0.781\end{array}$ & $\begin{array}{l}-- \\
0.407 \\
0.000\end{array}$ & $\begin{array}{c}-- \\
2.158 \\
--\end{array}$ & $\begin{array}{c}-- \\
0.878 \\
1.000\end{array}$ \\
\hline $\begin{array}{l}\text { Knowledge BF Benefits } \\
\text { Health } \\
\text { High } \\
\text { Medium } \\
\text { Low }\end{array}$ & $\begin{array}{c}-- \\
1.608 \\
0.762\end{array}$ & $\begin{array}{l}-- \\
0.774 \\
0.000\end{array}$ & $\begin{array}{c}-- \\
3.342 \\
--\end{array}$ & $\begin{array}{c}-- \\
0.203 \\
1.000\end{array}$ \\
\hline $\begin{array}{l}\text { Knowledge BF Benefits o } \\
\text { High } \\
\text { Medium } \\
\text { Low } \\
\text { Constante }\end{array}$ & $\begin{array}{c}-- \\
0.973 \\
-- \\
174.954\end{array}$ & $\begin{array}{c}-- \\
0.442 \\
-- \\
--\end{array}$ & $\begin{array}{c}-- \\
2.143 \\
-- \\
--\end{array}$ & $\begin{array}{c}-- \\
0.946 \\
-- \\
0.001\end{array}$ \\
\hline
\end{tabular}

*Index of Socioeconomic Levels created by the Mexican Association of Market Intelligence and Opinion agencies. A/B and D are considered the best and worst socioeconomic status respectively. ${ }^{* *}$ Odds ratio

the decision on infantile feeding ${ }^{29}$. Likewise, it would be essential to determine the knowledge that health professionals possess regarding breastfeeding since they are vital in transmitting the correct information to the population. Specifically, we can mention the inclusion of odontologists as actors for pro-breastfeeding spreading 
and action. They ought to constantly inform their patients about the benefits breastfeeding offers to the oral health of their soon-to-be newborn, benefits which are not widely known by the general population and in some cases even by people in the odontology field.

\section{Conclusion}

Pregnant women within this population have an acceptable amount of knowledge of the benefits which BF offers; however, there are topics that can be improved, like the benefits of BF in the health of the baby and the mother. Moreover, most pregnant women presented a neutral attitude towards infantile feeding, and less than half of the participants had the intention to practice EBF. On the other hand, the intention to breastfeed was linked to factors like age, occupation, socioeconomic status, number of children, and attitude. Housewives with a better socioeconomic status showed the greatest probability to have the intention to breastfeed their future babies

\section{Acknowledgments}

The authors thank to health jurisdiction VII, especifically Dr. María Magdalena Solís Medina, Dr. Gerardo Muñoz Picón and Social worker Lucy.

\section{Financing}

Master's degree scholarship by the National Council of Science and Technology (CONACYT by its Spanish acronym) (Number-719860).

\section{Conflict of interest}

The authors declare not to have any conflicts of interest.

\section{Ethical disclosures}

Protection of human and animal subjects. The authors declare that the procedures followed were in accordance with the regulations of the relevant clinical research ethics committee and with those of the Code of Ethics of the World Medical Association (Declaration of Helsinki).

Confidentiality of data. The authors declare that they have followed the protocols of their work center on the publication of patient data.
Right to privacy and informed consent. The authors have obtained the written informed consent of the patients or subjects mentioned in the article. The corresponding author is in possession of this document.

\section{References}

1. Organización Mundial de la Salud. Estrategia Mundial Para la Alimentación del Lactante y el Niño Pequeño. Washington, DC: Organización Mundial de la Salud; 2003.

2. Instituto Nacional de Salud Pública y UNICEF México. Encuesta Nacional de Niños, Niñas y Mujeres 2015. México, DF: Instituto Nacional de Salud Pública y UNICEF México; 2016.

3. Organización Mundial de la Salud. La Alimentación del Lactante y del Niño Pequeño. Capítulo Modelo Para Libros de Texto Dirigidos a Estudiantes de Medicina y Otras Ciencias de la Salud. Washington, DC: Organización Mundial de la Salud; 2010.

4. León N, Lutter CH, Ross J, Martín L. Cuantificación de los Beneficios de la Lactancia Materna: reseña de la Evidencia. Washington, DC: Organización Panamericana de la Salud; 2002.

5. Asociación Española de Pediatría. Manual de Lactancia Materna De la Teoría a la Práctica. Panamericana, Madrid España: Asociación Española de Pediatría; 2008.

6. Heinig M. Host Defense benefits of breastfeeding for the infant: effect of breastfeeding duration and exclusivity. Pediatr Clin Nort Am. 2001;48:105-23.

7. Enlow DH, Poston WR. Crecimiento Maxilofacial. México, DF: Interamericana; 2000.

8. Caravalho GD. Síndrome do respirador bucal ou insuficiente respirador nasal. Rev Secret Saúde. 1996;2:22-4.

9. Cai X, Wardlaw T, Brown DW. Global trends in exclusive breastfeeding. Int Breastfeed J. 2012;7:12.

10. González T, Escobar L, González LD, Rivera JÁ. Infant feeding practices and deterioration of breastfeeding in Mexico. Salud Pub Mex. 2013; 55:170-9.

11. Gerónimo R, Magaña M, Zetina E, Herrera Y. Conocimiento, actitud y práctica sobre lactancia materna en mujeres de período de posparto de un hospital de tercer nivel. Salud Tabasco. 2014;201:14-20.

12. Domínguez $M$, Rodríguez M, Ramos M. Información que Poseen las Madres Adolescentes Entre 12 y 17 Años Sobre la Lactancia Materna en el Período Post-parto Para la Redacción de un Programa en el Hospital General de los Valles del Tuy "Simón Bolívar". (tesis) Universidad Central de Venezuela; 2009.

13. Aznar F, Salazar S, Delgado X, Cani T, Cluet I. Evaluación del conocimiento de las madres sobre Lactancia Materna. Estudio multicéntrico en las áreas metropolitanas de Caracas y Maracaibo. Arch Venez Puer Ped. 2009;72:118-22.

14. Jessi M, Farmer AP, Maximova K, Willows ND, Bell RC. Predictors of exclusive breastfeeding: observations from the Alberta pregnancy outcomes and nutrition (APrON) study. BMC Pediatr. 2013;13:77.

15. Scott JA, Binns CW, Graham KI, Oddy WH. Temporal changes in determinants of breastfeeding initiation. Birth. 2006;33:37-45

16. Hamade H, Naja F, Keyrouz S, Hwalla N, Karam J, Al-Rustom L, et al. Breastfeeding knowledge, attitude, perceived behaviour, and intention among female undergraduate university students in the Middle East: the case of Lebanon and Syria. Food Nytr Bull. 2014;2:179-90.

17. Kavanagh KF, Lou Z, Nicklas JC, Habibi MF, Murphy LT. Breastfeeding knowledge, attitudes, prior exposure, and intent among undergraduate students. J Hum Lact 2012;28:556-64.

18. Hamade $H$, Chaaya M, Saliba M, Chaaban R, Osman H. Determinants of exclusive breastfeeding in an urban population of primiparas in Lebanon: a cross-sectional study. BMC Public Health 2013;13:702.

19. Álvarez Patricia. Propuesta de Intervención Para Promover una Práctica Correcta de la Lactancia Materna Exclusiva en Adolescentes Embarazadas de Santo Tomas Ajusco. (Tesis de Maestría) Instituto Nacional de Salud Pública; 2013.

20. Aguilar HJ, Coronado A, Gómez OJ, Cobos H. Adaptación de la iowa infant feeding attitude scale en población mexicana. Acta Pediatr Mex. 2016;37:149-58

21. Nommsen L, Dewey K. Development and validation of the infant feeding intentions scale. Matern Child Health J. 2009;13:334-42.

22. Peres KG, Cascaes AM, Nascimento GG, Victora CG. Effect of breastfeeding on malocclusions: a systematic review and metaanalysis. Acta Pædiatr 2015;104:54-61.

23. Abate A, Cavagnetto D, Fama A, Maspero C, Farronato G. Relationship between breastfeeding and malocclusion: a systematic review of the literature. Nutrients. 2020;12:3688. 
24. Jiménez ML, Pardo V, Ibáñez E. La influencia del profesional sanitario en la lactancia materna. Med Nat. 2009;3:77-85.

25. Nnebe UH, Racine EF, Laditka SB, Coffman MJ. Associations between perceived value of exclusive breastfeeding among pregnant women in the United States and exclusive breastfeeding to three and six months post-partum: a prospective study. Int Breastfeed J. 2016;11:8.

26. Leshi O, Samuel F, Aiakaye M. Breastfeeding knowledge, attitude and intention among female young adults in Ibadan, Nigeria. Open J Nurs. 2016;6:11-23.
27. Luisa A. Medición del Control Conductual Percibido Relacionado con la Lactancia Materna: diseño y Validación de una Escala Para Mujeres Embarazadas de la Ciudad de México. (Tesis) UNAM; 2017.

28. Niño R, Silva G, Atalah E. Factores asociados a la lactancia materna exclusiva. Rev Cil Pediatr. 2012;83:161-9.

29. Estrada J, Amargós J, Reyes B, Guevara A. Intervención educativa sobre lactancia materna. Rev AMC. 2010;14:2. 